\title{
Rail Energy Efficiency Improvement by Combining Coasting and Regenerative Braking
}

\section{L.A. Allen and S.I. Chien}

\author{
John A. Reif, Jr. Department of Civil and Environmental Engineering \\ New Jersey Institute of Technology, Newark, New Jersey \\ United States of America
}

\begin{abstract}
This paper synergizes the energy-saving strategies of coasting and regenerative braking in electric passenger trains to minimize energy consumption. Rail vehicles are generally not large consumers of energy, due to the small coefficient of friction at the steel-to-steel contact surface between the wheels and the running rails. However, a considerable amount of energy is required to accelerate a train from rest due to the high starting currents of electric motors and the large inertia to be overcome to set the train in motion. As the speed is increased, the propulsion resistance increases exponentially, and so does the energy consumption rate, making energy efficiency improvement necessary to increase the viability of rail operations. Coasting uses the momentum of the train to maintain motion with propulsion disabled. Regenerative braking captures the kinetic energy of the train and converts it into electrical energy on application of the brakes. These strategies are examined both individually and collectively to arrive at the most energy-efficient combination. A deterministic model is developed which calculates the speed and position of the train, and determines which deceleration method is more efficient, given the existing circumstances, so that energy efficiency is maximized.
\end{abstract}

Keywords: energy-efficiency, coasting, regenerative braking, power, motion regimes, electric train, rail.

\section{Introduction}

Urban gridlock and highway congestion have fuelled renewed interest in rail travel. Concerns about the environment concerning carbon monoxide and greenhouse gas emissions have led to an increased collective effort between federal, state and local officials to promote mass transit, and discourage private vehicle use. This initiative has seen vehicle miles driven declining since 2004 even though the economy has 
shown improvement [1]; an indication that the switching of modes was not entirely due to economic circumstances. Also of note is the fact that a $34 \%$ growth was recorded in the number of trips taken on transit for the years 2005 to 2011 [2].

Rail vehicles are operated in either electric or diesel mode and have proven that they are one of the most reliable modes for both inter-urban and intra-urban travel. Furthermore, their high capacity, safety and reliability have put them at the forefront of transportation sustainability [3]. The number of stops a train makes has a major influence on energy demand, therefore from a theoretical standpoint, the most energyefficient trip would be one devoid of any intermediate stops [4]. Except for streetcars, they do not compete with other surface transportation modes for use of streets or highways. This advantage allows them to travel at higher average speeds without outside interference from regular traffic signals or other transportation modes, allowing the train to experience almost constant fluidity.

Electric trains are more energy-efficient than their diesel counterparts are, they are $35 \%$ cheaper to operate and emit $20-35 \%$ less carbon per passenger mile travelled [5]. However, because of the high inrush of current required to start their traction motors, electric trains consume an exceptionally high amount of energy on acceleration. The same is true for diesel locomotives, which are essentially electric locomotives powered by on-board diesel generators, and all other rail vehicles which utilize electric traction. Since energy used for propulsion is the largest single expense for rail operators, there has been a concerted effort to reduce this cost and make rail operations more sustainable.

This research focuses on the application of the energy-saving strategies of coasting and regenerative braking to simulate a model of the train both individually and synergistically to achieve energy efficiency. Development was also made of a multitrain model and a substation electrical network model for a more realistic simulation. The strategies used to save energy cause the train to decelerate, resulting in a decrease in its kinetic energy. Therefore the applicability of each strategy whenever there was need to reduce the speed of the train was explored, and a determination was made as to which application gave a greater energy saving. However, although the strategies are combined, there is never an instant during which the train can be simultaneously coasting and regenerating. For regenerative braking to take place, the train must be in braking mode, whereas, in the coasting regime, the brakes must be inactive.

Coasting utilizes the momentum of the train to maintain motion with propulsion disabled; therefore, no energy is consumed. Regenerative braking converts the kinetic energy of the train into electrical energy by forcing the traction motors to run as generators and produce electrical energy. This electric energy is either used to accelerate other trains in close proximity, or stored for later use. The resulting reduction in kinetic energy causes the train to decelerate.

This paper expands on work done in [6]. Reviews of several other studies in rail energy conservation and featuring the strategies of coasting and regenerative braking were added to the literature review section. The literature review was also expanded to include a discussion on the available technologies for energy storage and the 
advantages and drawbacks of the chosen methods. In addition, a multi-train simulation with a model of the substation electrical network was added to improve the accuracy of the model. In the case study section, several sensitivity analyses were added to enhance the validity of the model and to reinforce the theories developed therein. For example, the sensitivity analyses of travel time to maximum allowable speed, energy savings to maximum speed and energy to number of cars were added. It should be noted that increasing the number of cars on the train could be viewed as increasing the train weight since the train is simulated as a point mass.

The remainder of the paper is arranged as follows: Section 2 consists of a comprehensive literature review of prior works involving energy conservation in the areas of speed profile optimization and energy recovery using multi-train modelling. In Section 3, a methodology is outlined, which includes the formulation of the model. A case study is presented in Section 4 along with a verification of the model while Section 5 concludes the present study and offers suggestions future research.

\section{Literature review}

Generally, the methods by which rail energy is conserved can be divided in to two distinct categories. First, there is conservation by minimizing the energy consumed by the train. This method involves some amount of coasting and is referred to in the literature as speed profile optimization; whereby it has a great influence on energy consumption [7]. One or more of the train parameters such as speed and tractive effort is adjusted at pre-determined points along the way for pre-determined lengths of time, to reduce the power consumption. The second category is energy recovery and involves the capture and reuse of the train's kinetic energy. The literature on these energy saving methods is reviewed separately in the following sections.

\subsection{Speed profile optimization}

In rail operations, most of the energy consumed during motion is used to overcome the various elements of train resistance. These include inertia, grade resistance and running resistance. Inertia refers to the force that resists the acceleration of the train from rest, while grade resistance is a negative force experienced during an uphill climb. Running resistance refers to the negative forces experienced by the train while in motion. It is typically dominated by the air resistance which is proportional to the square of the speed of the train, but also consists of bearing and track resistance [8]. Train motion normally consists of three regimes: acceleration, constant speed and deceleration (coasting and braking). The constant speed and coasting regimes though not essential for train operation are necessary for energy and time minimization purposes.

The literature indicates that the ideal optimal movements consist of rapid acceleration, followed by a period of coasting and a braking regime consisting of rapid deceleration $[9,10]$. The aim is to generate a set of energy-efficient speed profiles representing the speed trajectory of the train, with the independent variable being either distance or time. The optimal profiles would depend on the prevailing 
circumstances. If the train is early, the operator may want to concentrate on energy conservation. If the train is late, the aim will be to minimize the travel time.

A single coasting point is usually adequate in a system with short inter-station distances, except in cases of extreme topographic variations and speed restrictions, where operation is severely impacted. Under those circumstances, additional coasting points may be necessary [10].

In 1980, Milroy [12] proposed three motion regimes, namely acceleration, coasting and braking for optimal control on short station spacings. He determined that optimal operation depends on the points at which the switching between the regimes is accomplished. Liu and Golovitcher [13] determined that energy-efficient speed profiles could be obtained through the calculation of the switching points of the coasting and braking phases of a train. Taking into consideration the limits to traction, braking and velocity, and the effects of extreme topographical elements on the motion of the train, they developed a program for finding the sequence of controls for optimal operation and schedules. Uher and Disk [14] devised a method for the determination of the switching points between the powering and coasting regimes and that between coasting and braking. Their approach was one where the powering regimes were simulated in the forward direction, while the deceleration regimes were simulated in the reverse direction. The intersection points of the regimes represented the switching points.

Some other studies used heuristics to determine the optimal speed profiles. In that case, iterative methods were used to generate the optimal speed profiles. Bocharnikov et al. [15] used genetic algorithms to find the optimal train energy savings on a single train simulation. Kim and Chien [16] used a simulated annealing algorithm to iteratively generate optimal speed profiles in their study. They considered the constraints imposed by alignment elements such as gradient and determined that for maximum energy savings, optimal combinations of the motion regimes need to be applied. Khmelnitsky [17] developed numerical algorithms to minimize energy consumption on variable grades by employing the method of maximum principle. Dominguez et al [18] optimized the speed profiles of a train that was fitted with an Automatic Train Operation (ATO) system in which they used a Multi-objective Particle Swarm method. Other studies used analytical methods developed from basic equations of motion to develop the optimal speed profiles and determine the least energy-intensive trajectory for a given station-to-station movement $[19,20]$.

\subsection{Energy recovery}

Energy recovery in this context refers to the capturing of the kinetic energy of a braking train, either for immediate use by an accelerating train, or to be stored in an appropriate medium for later use in a subsequent acceleration cycle. Studies have shown that the use of an energy storage system can result in a $10 \%$ improvement in the energy efficiency of the system [21]. There is even energy savings to be obtained by optimizing regenerative braking in high-speed rail where the braking frequency is low [22]. On the other hand, the direct transmission of regenerated energy to an 
accelerating train, though much more economical in terms of cost of equipment, may not be achieved efficiently unless the receptivity of the system is high [23]. In this instance, receptivity refers to the ability to efficiently harness the regenerated energy, and may be improved by storing the energy in a wayside energy storage system (WESS) for subsequent reuse. The addition of these devices is aimed at reducing energy consumption through improved capture of regenerative braking energy and reduced energy costs through reduction in peak power demand [24], which can be as much as $25 \%$ of the overall electricity cost [25]. Miyatake and Ko [26] suggested the optimization of the charging and discharge cycles of the WESS as a means of ensuring adequate receptivity. They conducted a related study, which achieved a 5.67\% energy saving when the storage device was an Electrostatic Double-Layer Capacitor (EDLC).

Although regenerative braking significantly retards the speed of the train, it will not hold the train at rest, and therefore the friction brakes are supplemented with the pneumatic brakes. The two braking systems are merged in a process called blending. Puigi et al. [27] conducted a study that predicted braking performance and underscored the importance of blending when electric and pneumatic brakes are applied in tandem. Regenerative braking and subsequent acceleration using regenerated energy can be thought of as a large positive consumption of energy on acceleration, and a large negative consumption on braking. This results in low voltage at point of acceleration and high voltage at the point of braking. Installation of a WESS helps to alleviate this problem by supplying propulsion energy at the point of acceleration and providing a storage medium for the regenerated energy at the point of braking, thus providing voltage regulation. In addition, it may provide backup power in case of electricity outages.

\subsubsection{Available technologies}

There are several storage media that can be considered in the design of a WESS. However, the selection of a storage medium may depend on several design factors such as the length of time for which the energy is required to be stored, the energy density required, the power density required, efficiency or the tolerable self-discharge rates. Lead-acid cells, nickel metal hydride (NiMh) or lithium ion batteries have high energy densities, efficiencies and low self-discharge rates while flywheels and EDLCs are known for their high-power densities and long-life cycles; two properties required for rail operation. Flywheels have the disadvantage of high self-discharge rates, while EDLCs have low energy densities. Table 1 outlines the performance indicators of the various technologies utilized in WESS applications.

\subsection{Integrated optimization}

Integrated optimization refers to the combining of two or more energy-saving methods into one model in order to synergize them. In this study, coasting and regenerative braking are jointly considered in a model to examine the integral benefits, while most other studies assessed their performances separately. Hull [28] in his research, obtained a $23 \%$ energy reduction with regeneration, and a $22 \%$ reduction using coasting. There was however, not much related literature found where the two energy saving strategies were combined into one model. 


\begin{tabular}{|c|c|c|c|c|c|c|}
\hline \multicolumn{2}{|c|}{ Storage technology } & $\begin{array}{l}\text { Energy } \\
\text { density } \\
\text { (Wh/kg) }\end{array}$ & $\begin{array}{l}\text { Power } \\
\text { density } \\
(\mathrm{W} / \mathrm{kg})\end{array}$ & $\begin{array}{l}\text { Self-discharge } \\
\text { rate (monthly } \\
\% \text { of rated } \\
\text { capacity) }\end{array}$ & $\begin{array}{l}\text { Life } \\
\text { cycle } \\
\text { (cycles) }\end{array}$ & $\begin{array}{l}\text { Efficiency } \\
(\%)\end{array}$ \\
\hline \multicolumn{2}{|c|}{ Super capacitors (EDLC) } & $2.5-15$ & $500-5000$ & 14 & $<10^{6}$ & $85-98$ \\
\hline \multicolumn{2}{|l|}{ Flywheels } & 100 & $1000-5000$ & $100 *$ & $10^{5}-10^{7}$ & 90 \\
\hline \multirow[t]{3}{*}{ Batteries } & Lead-acid & $5-100$ & 180 & 5 & $\begin{array}{l}1200- \\
1800 \\
\end{array}$ & $85-90$ \\
\hline & Nickel types & $50-80$ & $80-150$ & 10 & $\begin{array}{l}1500- \\
3000\end{array}$ & $65-80$ \\
\hline & Lithium types & $100-150$ & $100-350$ & 5 & 100 & $90-100$ \\
\hline
\end{tabular}

*Flywheels completely self-discharge within 24 hours

Table 1: Operating characteristics of various energy storage devices

\section{Methodology}

This section outlines a model that was developed to illustrate the simulation of the parameters of the alignment, including the topography, speed limit, and the specifications of the train that includes mass, motor power and number of cars. It includes equations for the calculation of speed, distance travelled, power drawn, and energy consumed in each time step throughout each motion regime and the development of the objective function. Plots of these parameters yielded the decision variables: tractive effort, speed, travel distance and energy consumption at every simulation step.

\subsection{Model formulation (single train)}

For the simulation of the parameters in this study, travel time was chosen as the independent variable and was incremented in very small steps. As a result, the acceleration achieved and the distances covered were also very small and assumed to be constant and represented by the averages over each time step. The train motion equations were developed for the four regimes namely: acceleration, cruising, coasting and braking. The propulsion and brake status of all the motion regimes are shown in Table 2.

\begin{tabular}{|c|c|c|}
\hline Regime & Propulsion status & Brake status \\
\hline Acceleration & Active & Inactive \\
\hline Cruising & Active & Inactive \\
\hline Coasting & Inactive & Inactive \\
\hline Braking & Inactive & Active \\
\hline
\end{tabular}

Table 2: Propulsion and brake status of the motion regimes

Propulsion is only active during the acceleration and cruising regimes, and as such, these are the only instances where power is consumed. On the other hand, regeneration 
occurs only during the braking regime. The following sections outline the equations describing the movement within the motion regimes and the consumption of energy therein.

\subsubsection{Acceleration}

The acceleration over an arbitrary alignment segment $i$ could be represented as the net tractive effort which is the divided by the equivalent mass of the train; this is the mass which was adjusted to include the effect of the rotating components. Figure 1 illustrates the forces acting on accelerating train and this depiction can represent the motion of the train in any segment of the journey.

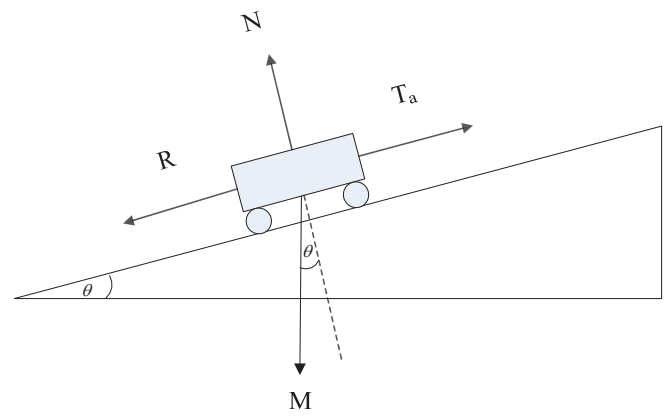

Figure 1: Forces acting on a body in motion

$$
a_{i}=\frac{\left(T_{a}(v)-R(v)\right)}{M_{e q}}
$$

In Equation (1), $T_{a}(v)$ is the applied tractive effort (lbw), $R(v)$ is the train resistance and $M_{e q}$ is the equivalent mass of the train. The train resistance is represented by the modified Davis equation [29]:

$$
R_{u}=0.6+\frac{20}{w}+0.01 V+\frac{k V^{2}}{w n}
$$

In Equation (2), $R_{u}$ refers to the unit resistance (lb/ton), $w$ is the weight per axle (tons), $V$ is the train speed $(\mathrm{mi} / \mathrm{h}), k$ is the air resistance coefficient and $n$ is the number of axles.

The acceleration could be denoted as the average acceleration $\bar{a}_{i}$, since the time increment is small, giving:

$$
a_{i} \approx \bar{a}_{i}=\frac{T_{n e t}}{M_{e q}}
$$

where $T_{n e t}$ is the tractive effort available for propulsion. 
The speed of the train can be represented as the integral of the acceleration with respect to time:

$$
v=\int a d t=\lim _{\Delta t \rightarrow 0} \sum_{i} \overline{a_{i}} \Delta t_{i}
$$

where $v$ denotes the train speed, and $\Delta t_{i}$ represents the length of a simulation step.

The change in speed is stated as:

$$
v_{i+1}-v_{i}=\overline{a_{i}} \Delta t
$$

The distance increment is represented as:

$$
s_{i+1}=s_{i}+\bar{v}_{i} \Delta t+\frac{1}{2} \bar{a}_{i} \Delta t^{2}
$$

The power utilized in the acceleration regime is given by:

$$
P_{a}(v)=T_{a}(v) d s=T_{a}(v) \bar{v}{ }_{i} \Delta t
$$

The energy consumed during acceleration is given by:

$$
E_{a}=\int P_{a} d t=\lim _{\Delta t \rightarrow 0} \sum_{i} T_{a}(v) \overline{v_{i}} \Delta t
$$

\subsubsection{Cruising}

In the cruising regime, there is no acceleration; therefore, the tractive forces exactly balance the resistive forces.

$$
T_{a}(v)=R(v)
$$

The speed is normally the maximum allowed by law or the maximum capability of the train (whichever is smaller), and in this regime, there is no acceleration.

The distance travelled in a time increment is given by:

$$
s_{i+1}-s_{i}=v_{\max } \Delta t
$$

The power consumed in the cruising regime is given by:

$$
P_{c}(v)=R(v) v_{\max } \Delta t
$$

The energy consumed during the cruising regime is given as:

$$
E_{c}=\int P_{c} d t=\lim _{\Delta t \rightarrow 0} \sum_{i} R(v) v_{\max } \Delta t
$$

\subsubsection{Coasting}

When the train is in coasting mode, there is no traction and thus no power consumed by the motors. Motion is maintained by the momentum of the train. The train would accelerate on a decline and decelerate on an incline or level track as it losses momentum. 
The acceleration is given by:

$$
a_{i}=\frac{-R(v)}{M_{e q}}
$$

\subsubsection{Regenerative braking}

On the application of the brakes, the motors are forced to run as generators thereby converting the kinetic energy of the train to electrical energy. This generated electrical energy which is fed to a wayside energy storage system (WESS) by way of the network transmission lines, to be stored until it is needed in the next acceleration cycle. It is important that the WESS can absorb most of the energy sent to it, or the remainder will be dissipated as heat in the braking resistors. This would defeat the purpose of regenerative braking and render the system inefficient.

This procedure is illustrated in Figure 2.

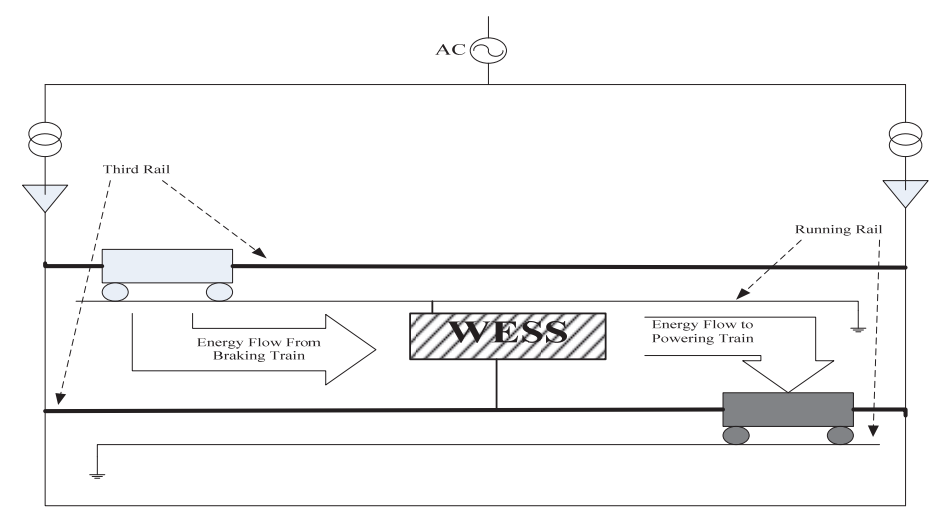

Figure 2: Wayside energy storage system (WESS)

The regenerated energy consists of three different components. There is a component resulting from the momentum of the train. It depends strictly on the speed and weight of the train. The second part is related to the gradient of the alignment section and is only positive when encountering a decline; otherwise it could be negative. The third part is negative and is related to the train resistance. Since this resistance acts against the motion of the train, it is negative. Equation (14) is a representation of the energy regenerated when the train brakes [30]:

$$
E_{R}=\left[0.01072 M_{e q}\left(v_{i}^{2}-v_{i+1}^{2}\right)+27.25 s_{i} M G_{i}-\left(\frac{0.2778 R_{i} s_{i}}{M}\right)\right] \eta_{R}
$$

where $G_{i}$ is the percentage gradient of segment $i, M$ is the mass of the train and $\eta_{R}$ is the regeneration coefficient which compensates for the inefficiencies of the charge and discharge cycles of the WESS as well as the traction motor efficiency and transmission line losses between the train and the WESS. 
This study seeks to minimize the energy drawn from the substation and since regenerative braking supplies energy to the system, it is subtracted from the total energy consumed.

The objective function is therefore:

$$
\begin{gathered}
\operatorname{Min}\left\{E_{a}+E_{c}-E_{R}\right\} \\
\text { st: } \\
v_{i} \leq v_{\max } \\
s_{i} \leq S \\
t_{i} \leq T
\end{gathered}
$$

where $t_{i}$ is the travel time on section $i$ and $S$ is the station.

\subsection{Multi-train model}

Present rail operations focus on safety and punctuality as major concerns, and therefore, energy efficiency is generally a secondary objective. However, by "padding" the timetable with small increases in the allowable trip time allows for the absorption of small delays, the implementation of the coasting regime or train-to-train transfer of braking energy.

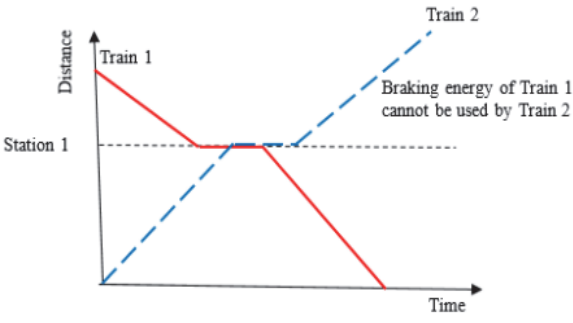

(a)

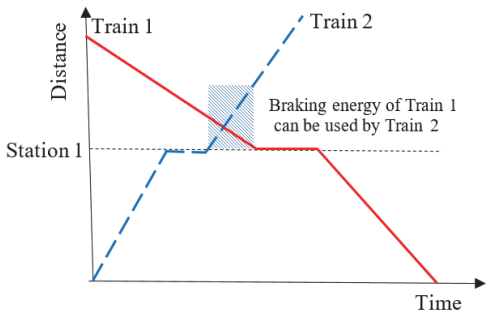

(b)

Figure 3: (a): Train 2 not receptive to Train 1 and (b) Train 2 receptive to Train 1

For instance, in the multi-train model, two trains leave from different stations and arrive at Station 1 at different times. In Figure 3 (a), since Train 1 and Train 2 are not simultaneously braking and accelerating, no energy transfer is possible. The timetable is rescheduled to allow for the adjustment of the dwell time of Train 2 at Station 1 to coincide with the braking regime of Train 1 into Station 2 as shown in Figure 3 (b). Train 2 could therefore absorb acceleration energy recovered from the braking regime of Train 1 [31].

\subsubsection{Substation model}

The power network can be represented by an uplink and a downlink section of alignment between two stations as shown in Figure 4. It could be further simplified 
and modelled as an ideal direct current (dc) voltage source connected in series with a resistance and a diode. The voltage source represents the line voltage, the resistance is the line resistance and the diode prevents the flow of power back to the substation. If the line voltage is less than the no-load voltage of the network, the substation delivers power to the network. If the line voltage is greater than the no-load voltage of the network, there is no flow of power because the diode acts like an open circuit with resistance of the order of several $\mathrm{M} \Omega$.

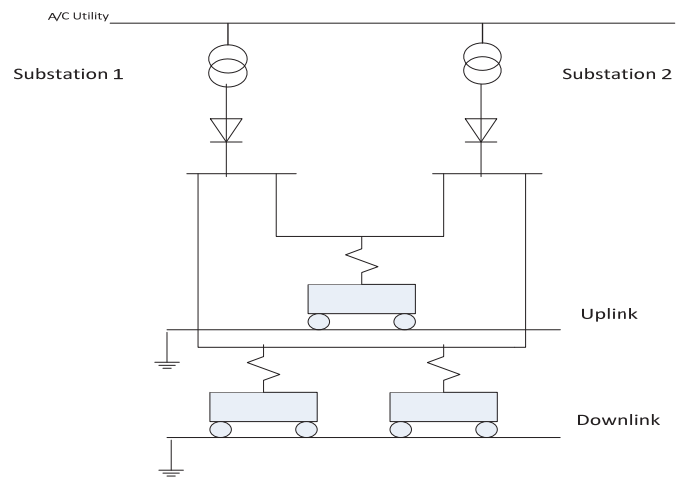

Figure 4: The electrical network power model

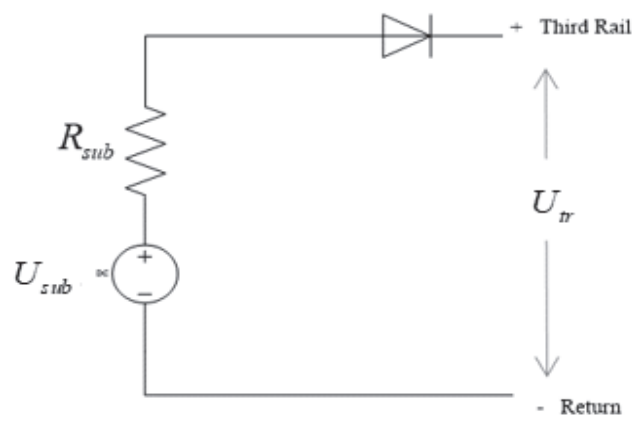

Figure 5: Substation model

The mechanical power required for the station-to-station travel is given by:

$$
P_{m}=\sum_{t=0}^{T} F_{i} V_{i}
$$


where: $P_{m}$ is the mechanical power

$T$ is the maximum allowable travel time

$F_{i}$ is the tractive force applied on section $i$ and

$V_{i}$ is the speed on section $i$.

The electrical power required is represented by the piecewise function

$$
P_{e}= \begin{cases}\frac{P_{m}}{\eta_{n w}} & P_{m} \geq 0 \\ P_{m} \eta_{n w} & P_{m}<0\end{cases}
$$

where: $\quad P_{e}$ is the electrical power requirement and

$\eta_{n w}$ is the power network efficiency.

The power loss due to voltage drop in the transmission line is given as:

$$
P_{\text {loss }}=I_{v e h}^{2} R
$$

where:

$P_{\text {loss }}$ is the line loss for the simulation,

$I_{v e h}$ is the line current drawn by the train

and $R$ is the transmission line resistance $(\Omega)$.

However, the electrical power consumed by the train is:

$$
P=U_{\text {sub }} I_{\text {veh }}
$$

where:

$P$ is the electric power drawn by the train (W),

$I_{\text {veh }}$ is the line current (A),

and $U_{\text {sub }}$ is the transmission line voltage $(\mathrm{V})$.

So, substituting Equation (18) into Equation (17),

$$
P_{\text {loss }}=\frac{P^{2} R}{U_{\text {sub }}^{2}}
$$

\subsection{Case study}

A case study was conducted on Long Island Rail Road's Hempstead branch on a single station spacing between Jamaica and East New York stations; a distance of approximately 5 miles. The train was accelerated uniformly to maximum speed and cycled through all the motion regimes. There were different pre-set values for the 
termination of the coasting regime, which allowed for adjustments to the amounts of coasting and regenerative braking. The two strategies complement each other so that a reduction in coasting implies an increase in regenerative braking and vice versa.

At this point, it is important to note that if $v_{\max }$ is chosen for the termination speed for coasting, then no coasting will take place and the brakes will be applied when the train is at maximum speed. The technical specifications of the railcar used in the study are listed in Table 3.

\begin{tabular}{|l|l|}
\hline Train specifications & Value \\
\hline Number of cars per train & 10 \\
\hline Number of traction motors & $4 / \mathrm{car}$ \\
\hline Motor power & $265 \mathrm{hp}$. \\
\hline Mass per car & $128,370 \mathrm{lbs}$. \\
\hline Maximum allowable speed & $80 \mathrm{mph}$. \\
\hline Maximum acceleration rate & $\pm 4.8 \mathrm{mph} / \mathrm{s}$ \\
\hline
\end{tabular}

Table 3: Railcar technical specifications

\subsection{Results and sensitivity analysis (Single coasting regime)}

In this section, the results obtained are presented, and the sensitivities of various parameters of the train are examined to ascertain how they react to changes in the decision variables.

A case study was conducted on the main line connecting Jamaica Station to East New York Station; a distance of 8,160.16 meters. The alignment consists of speed restrictions $v_{\max }$ of $72.4 \mathrm{~km} / \mathrm{h}$ between 0 to 1,954 meters from the Jamaica Station, 118 $\mathrm{km} / \mathrm{h}$ between 1954 and 6239.9 meters and $112.5 \mathrm{~km} / \mathrm{h}$ for the rest of the run. The alignment topography consists of the two stations at similar elevations with a dip between them. The WESS equipment is located at the stations and since the transmission lines are homogeneous, the internal resistance of the lines vary with the length of the lines, and in this case, the travel distance. Therefore, the line loss incurred in the internal resistance of the transmission line is directly proportional to the length of the transmission line.

\begin{tabular}{|c|c|c|c|c|c|c|}
\hline $\begin{array}{c}\mathrm{V}_{\mathrm{c}} \\
(\mathrm{km} / \mathrm{h})\end{array}$ & $\begin{array}{c}\text { Travel } \\
\text { Time } \\
(\mathrm{s})\end{array}$ & $\begin{array}{c}\text { Energy } \\
\text { consumed } \\
(\mathrm{kWh})\end{array}$ & $\begin{array}{c}\text { Braking } \\
\text { Distance } \\
(\mathrm{m})\end{array}$ & $\begin{array}{c}\text { Energy } \\
\text { regenerated } \\
(\mathrm{kWh})\end{array}$ & $\begin{array}{c}\text { Line loss } \\
(\mathrm{W}-\mathrm{hr})\end{array}$ & $\begin{array}{c}\text { Net energy } \\
\text { consumed } \\
(\mathrm{kWh})\end{array}$ \\
\hline 71.3 & 366.30 & 247.74 & 135.30 & 29.82 & 1.68 & 217.92 \\
\hline 82.3 & 351.35 & 255.30 & 180.31 & 33.84 & 1.33 & 221.46 \\
\hline 93.2 & 338.55 & 377.04 & 231.77 & 51.19 & 0.96 & 325.85 \\
\hline 104.2 & 331.20 & 414.65 & 288.23 & 63.69 & 0.65 & 350.96 \\
\hline 112.5 & 328.45 & 448.90 & 336.53 & 74.22 & 0.43 & 374.68 \\
\hline
\end{tabular}

Table 4: Energy consumed for various values of $V_{c}$ 
The results in Table 4 indicate that the net energy consumed by the train increases with increasing values of the coasting termination speed $\left(V_{c}\right)$. This is because of decreases in the coasting regimes associated with larger values of $V_{c}$.

The variation of the braking distance is because the more the train coasts, the slower it will be travelling when the brakes are applied. Therefore, the braking distance will be shorter. Also, the energy regenerated will be less with shorter braking distances.

\subsubsection{Speed profiles vs. the coasting termination speed}

With adjustment of the termination speed for the coasting regime, several speed profiles were generated to indicate the variation of speed of the train with time for different coasting termination speeds. The plots of profiles are depicted in Figure 6. As more coasting was added to the speed profiles, the travel time showed exponential increases. Therefore, coasting can be extended to save energy if the train is ahead of schedule, and can be progressively reduced to make up time if the train is late.

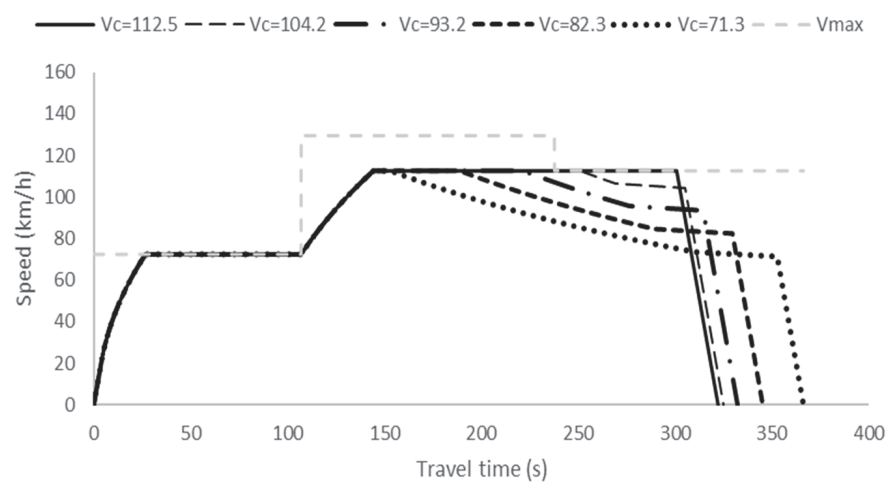

Figure 6: Speed- time plots for different coasting termination speeds

\subsubsection{Energy consumed vs. travel time (speed)}

In this section, the energy consumed with the application of coasting was examined separately from that consumed during the application of regenerative braking and the results were compared with the travel time. The two strategies were then combined to ascertain the level of synergy that can be accomplished.

It was noted that each energy-saving strategy, when applied individually, allowed the train to consume less energy than when no strategy was applied. Coasting causes the train to decelerate, unless a decline is encountered, where the train will accelerate. 


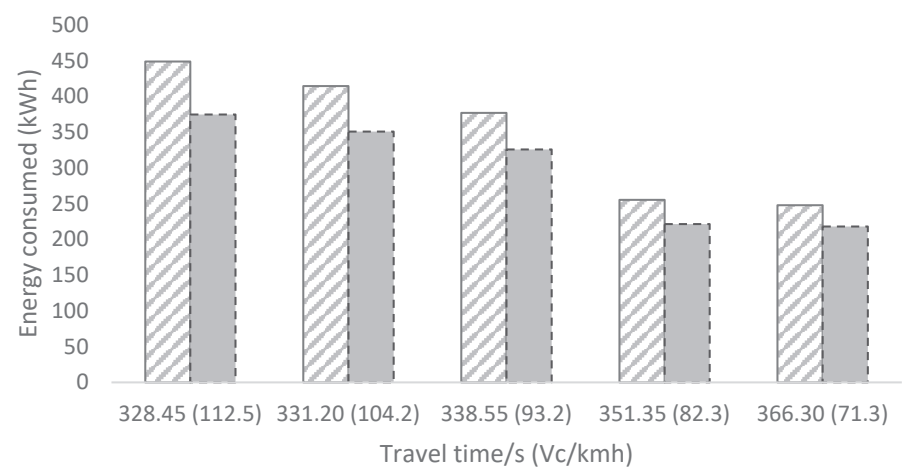

Figure 7: Energy consumed vs. travel time

When coasting terminates at higher speeds, the travel time is much shorter than when it terminates at lower speeds. The lack of momentum due to reduced kinetic energy contributes to the longer travel times. However, this property of the coasting regime can be used to shorten travel time when the train is running behind schedule or utilize extra time when the train is early. Figure 7 indicates how the travel time varies with the coasting termination speed and energy consumed.

Coasting saved more energy when the coasting termination speed $V_{c}$ was low, but increased the travel time, and regeneration was better when $V_{c}$ was higher but increased the energy consumption.

When the two strategies were combined, the combination outperformed the individual applications, yielding substantially more energy savings for most values of $V_{c}$.

\subsubsection{Travel time vs. maximum allowable speed}

Similar results are obtained when travel time is plotted against maximum speed for travel involving coasting and those where coasting was excluded. Such a plot is illustrated in Figure 8. In the simulations where coasting was involved, $V_{c}$ was fixed at $80 \mathrm{ft} / \mathrm{s}$. The Figure consists of only one plot each for "coasting" and "no coasting" operation, since the inclusion of regeneration does not affect the travel time. As such, the "coasting" plot would coincide with "coasting and regeneration" and the "no coasting" plot would include the "no coasting and no regeneration" and "regeneration only" plots. The plots indicate that travel time increases as the length of the coasting regime increases. 


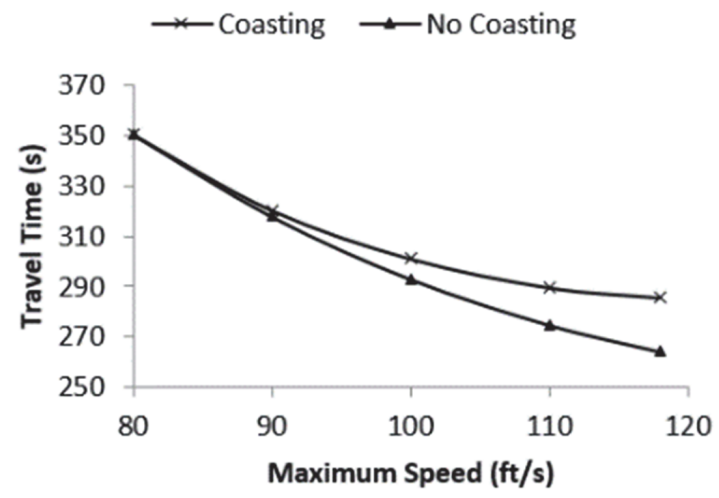

Figure 8: Maximum speed vs. travel time

\subsubsection{Energy consumed vs. maximum speed}

Figure 9 represents a plot of the energy consumed versus the maximum allowable travel time for the train.

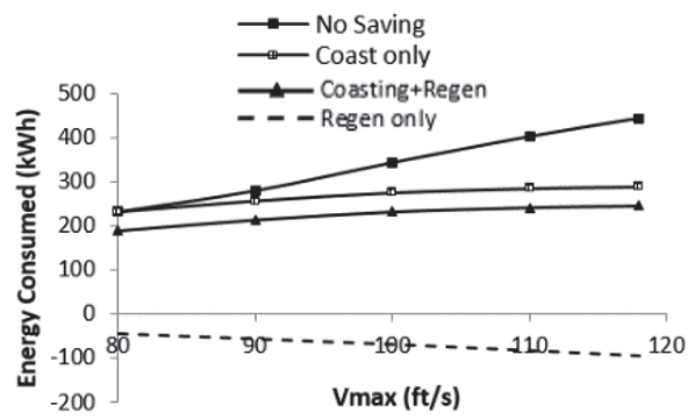

Figure 9: Energy consumed vs. maximum speed

In this case, $V_{c}$ is held constant at $80 \mathrm{ft} / \mathrm{s}$. As can be seen from the plot, the energy consumed without the use of an energy-saving strategy increased rapidly as the maximum speed was increased. However, when coasting was added to the travel, a considerable decrease in consumption was observed in comparison to the scenario when no energy-saving strategy was applied. The decrease grew larger as the maximum speed was increased due to additional quantities of coasting being added at higher $V_{\max }$ and fixed $V_{c}$.

When regenerative braking was the only energy-saving strategy applied, the amount of energy recovered was seen to increase as the maximum speed increased. However, in the case where regenerative braking was combined with coasting and added to the trip, there were additional increases in energy savings. Since the value of 
$V_{c}$ is constant, it means that equal amounts of energy would be regenerated for each value of $V_{\max }$, thus the plots for "coast only" and "coasting and regeneration" were seemingly parallel to each other.

\subsubsection{Energy saved vs. maximum speed}

Figure 10 shows plots of energy savings using coasting only, regenerative braking only and a combination of the two. For each strategy, the energy saved increases as the maximum speed increases. However, if coasting and regenerative braking were applied separately, the least energy-intensive operation would involve applying regenerative braking only for any value of maximum speed below $100 \mathrm{ft} / \mathrm{s}$ and coasting plus regenerative braking otherwise. When coasting and regenerative braking are combined, it could be seen that the combination is by far the most energy-efficient above a maximum speed of $63 \mathrm{mph}$.

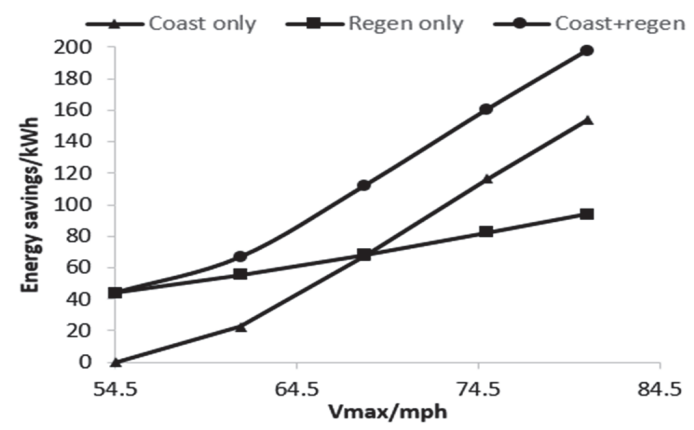

Figure 10: Energy savings vs. Maximum speed

\subsubsection{Energy consumed per car vs. number of cars per train}

It could be seen that the energy consumed per car decreases almost exponentially as the trains are made longer. This is also an indication of the increased energy stored in heavier trains in motion, which is advantageous for both coasting and regeneration.

Without an energy-saving strategy included, the kinetic energy of the train is wasted as heat in the braking resistors on application of the brakes, hence this option consumes the most energy. When the coasting strategy is applied, the momentum of the train is utilized to propel it with the propulsion system disabled. This strategy therefore consumes less energy than when no energy-saving strategy is applied. When regenerative braking is synergized with the coasting strategy, considerably less energy is consumed as shown in Figure 11, and thus this is the preferred mode of operation for maximum energy savings.

\subsubsection{Mechanical power drawn vs. travel time}

Figure 12 shows that at the beginning of the travel, the mechanical power consumed rises sharply from the origin to approximately $3700 \mathrm{~kW}$. It fluctuates as the train 
accelerates, then it slowly stabilizes as the train attains maximum speed. Those fluctuations were probably due to the changes in the alignment geometry encountered by the train and a speed restriction at $66 \mathrm{~km} / \mathrm{h}$, which created a demand for greater torque at the slower speed.

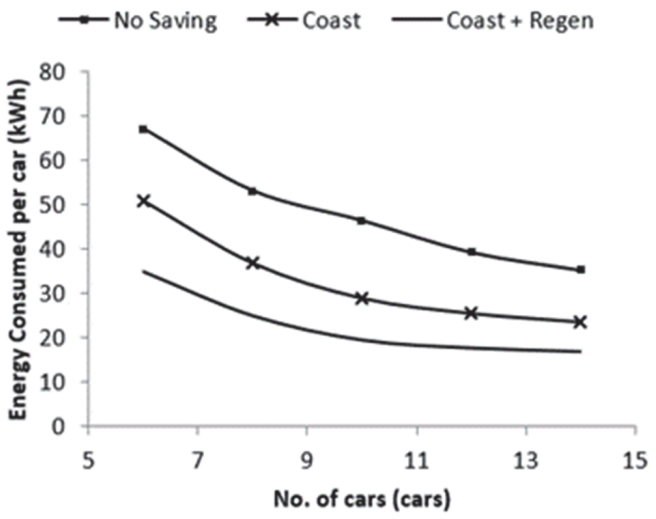

Figure 11: Energy consumed per car vs. number of cars

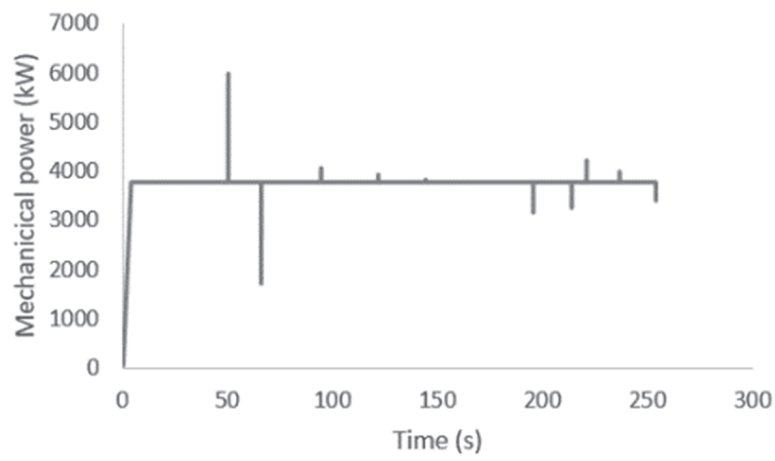

Figure 12: Plot of mechanical power consumed vs. time

\subsection{Results and sensitivity analysis (Multiple coasting regimes)}

The train was also simulated with the speed profiles containing multiple coasting regimes. The simulations were compared according to what the speed was after the first coasting regime, while braking distances were kept constant. For example, in each simulation, the first coasting regime began when the train was travelling at 102.6 $\mathrm{m} / \mathrm{s}$. If the coasting regime ended at $90 \mathrm{~m} / \mathrm{s}$, then in Figure 13 it was designated is " 90 dip". The results are contained in Table 5. 


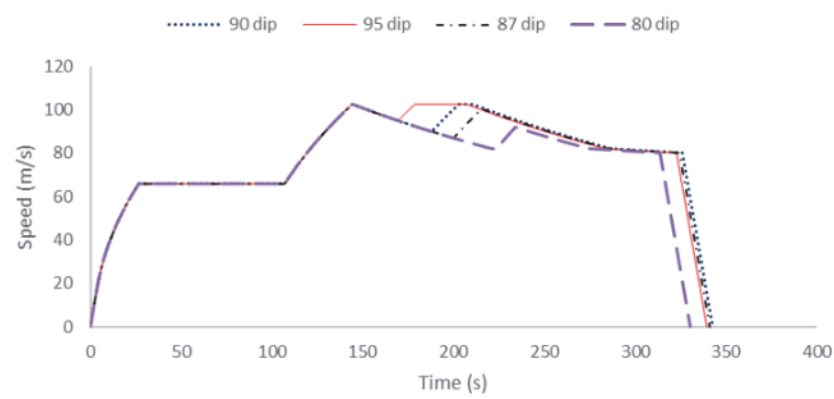

Figure 13: Time/Speed plots with multiple coasting regimes

The lower the dip after the first coasting regime, the shorter is the second cruising regime. In the 87 and 82 dips, there was no second cruising regime and the energy used was less than when a second cruising regime was applied.

\begin{tabular}{|c|c|c|c|c|c|}
\hline $\begin{array}{c}\text { Min. coast } \\
\text { speed }(\mathrm{m} / \mathrm{s})\end{array}$ & $\begin{array}{c}\text { Energy } \\
\text { consumed }(\mathrm{kWh})\end{array}$ & $\begin{array}{c}\text { Travel time } \\
(\mathrm{s})\end{array}$ & $\begin{array}{c}\text { Regenerated } \\
\text { energy }(\mathrm{kWh})\end{array}$ & $\begin{array}{c}\text { Line loss } \\
(\mathrm{kWh})\end{array}$ & $\begin{array}{c}\text { Net energy } \\
\text { consumed }(\mathrm{kWh})\end{array}$ \\
\hline 95 & 326.35 & 339.40 & 33.84 & 1.42 & 292.51 \\
\hline 90 & 299.08 & 342.60 & 33.84 & 1.51 & 265.24 \\
\hline 87 & 288.08 & 341.00 & 33.84 & 0.702 & 254.24 \\
\hline 82 & 279.40 & 330.30 & 33.84 & 0.656 & 245.56 \\
\hline
\end{tabular}

Table 5: Results from simulation of multiple coasting regimes

In Table 5, the results also indicate that replacing the cruising regime with additional coasting and subsequent acceleration can substantially reduce energy consumption although the travel time remains practically the same.

\section{Conclusion and recommendations for further studies}

The aim of this research was to synergistically combine the energy-saving strategies of coasting and regenerative braking as it relates to electric rail vehicles on the section of alignment in question. In so doing, energy-efficient operation was sought using a simulation framework. A deterministic model was developed which calculated the speed and position of the train, and determined which deceleration method was more efficient, given the existing circumstances, so that energy efficiency was maximized.

While both strategies individually lowered the energy consumption of the train, the combination of coasting and regenerative braking significantly lowered the consumption for most values of the coasting termination speed in the single coasting regime simulation. In addition, coasting was most effective when it was terminated at low speeds, while regeneration was more energy-efficient when initiated at higher values of the coasting termination speed. The energy savings achieved with coasting 
only ranged between 0 and $35 \%$, that for regenerative braking only was between 10 and $23 \%$ and the range for the combination of the two was 20 to $45 \%$.

The multiple coasting regime simulation saw more energy-efficient operation than when a large cruising regime is applied. It can therefore be concluded that the replacement of the cruising regime with multiple coast an acceleration cycles may promote more energy-efficient operation.

Further work is recommended in the areas of optimization of the size (storage capacity) of the WESS and the locations for its placement along the wayside. Since the cost of a WESS increases with size, the system designer may want to determine the maximum number of trains that would regenerate to or draw energy from a WESS in a particular section of track at a particular time. The inability of a WESS to satisfy either of those requests would render the system inefficient. Further, the actual location of the WESS is of great importance, since transmission line losses increase with increasing distance between the WESS and third rail. Therefore, the optimal location for each WESS is also recommended to boost the effectiveness of the storage system and increase the efficiency of the operation.

\section{References}

[1] D.C. Grisby, "A New Partnership: Rain Transit and Convention Growth", American Public Transportation Association, Washington DC, USA, September 2013.

[2] American Public Transportation Association: 2012 Public Transportation Fact Book, Washington, DC, USA, September 2012.

http://www.apta.com/resources/statistics/Documents/FactBook/APTA_2012_

Fact\%20Book.pdf Accessed October 10, 2015.

[3] V.R. Vuchic, "Urban Transit: Systems and Technology", John Wiley and Sons, Hoboken, USA, 2007.

[4] International Union of Railways, "Evaluation of Energy Efficient Technologies for Rolling Stock and Train Operation of Railways" Deutsche Bahn AG, Railway Environmental Centre, Berlin Institute for Future Studies and Technology Assessment, Berlin, Germany, 2003.

[5] American Public Transportation Association, "Transit on the Cutting Edge of Clean Technology", Policy Development and Research, September 2012.

[6] L.A. Allen, S.I. Chien, "Examination of the Contributions of Coasting and Regenerative Braking to the Efficiency of Electric Rail Vehicles", J. Pombo, (Editor), Proceedings of the Third International Conference on Railway Technology: Research, Development and Maintenance, Civil-Comp Press, Stirlingshire, UK, 2016. doi: 10.4203/ccp.110

[7] X. Li, H.K. Lo, "Energy minimization in the dynamic scheduling and control of metro rail operations", Elsevier Transportation Research Part B, 70, 269-284, 2014.

[8] A.T Dover, "Electric Traction: A Treatise to the Application of Electric Power to Tramways and Railways", Macmillan Company, New York, USA, 1917. 
[9] P. G. Howlett, P. J. Pudney, "Energy-efficient Train Control”, Springer-Verlag London Ltd, 1995.

[10] K.K. Wong, T.K. Ho, "Dynamic Coast Control of Train Movement with Genetic Algorithm", International Journal of System Science, 35(13-14), pp. 835-846, 2004.

[11] M. Thong, A. Cheong, "Energy Efficiency in Singapore's Rapid Transit System", Journeys, 38-47, May, 2012,

[12] I.P. Milroy, "Aspects of Automatic Train Control", PhD Thesis, Loughborough University of Technology, July, 1980.

[13] R. Liu, I.M. Golovitcher, "Energy-efficient operation of rail vehicles", Elsevier Transportation Research Part A, 37, 917-932, 2003.

[14] R.A. Uher, D.R. Disk, "A Train Operations Computer Model”, Rail Systems Center, Carnegie Mellon University, Pittsburgh, USA, Union Switch \& Signal Company, American Standard Inc., Pittsburgh, PA, USA, 1987.

[15] Y.V. Bocharnikov et al, A.M. Tobias, C. Roberts, S. Hillmansen, C.J. Goodman, "Optimal driving strategy for traction energy savings on DC suburban railways", IET Electric Power Applications, 1(5): 675-682, October 2007.

[16] K. Kim, S. Chien, "Optimal Train Operation for Minimum Energy Consumption Considering Track Alignment, Speed Limit and Schedule Adherence", Journal of Transportation Engineering, Vol. 137, pp. 665-674, 2011.

[17] E. Khmelnitsky, "On an optimal control problem of train operation" in IEEE Transactions on Automatic Control, Vol 45, no. 7, pp 1257-1266, July 2000.

[18] M. Dominguez, "Multi objective particle swarm optimization for the design of efficient ATO speed profiles in metro lines", Engineering Applications of Artificial Intelligence, Vol 29, pp43-53, March 2014.

[19] S. Yeh, "Integrated Analysis of Vertical Alignments and Speed Profiles for Rail Transit Routes", Master's Thesis, University of Maryland, College Park, USA, 2003.

[20] L. Allen, S. Chien, "Optimization of Rail Energy Conservation Through the Adoption of Varying Coasting Strategies: A Case Study of the Long Island Rail Road's Flatbush Branch", Transportation Research Board 93rd Annual Meeting, Washington, USA, 2014.

[21] R. Conti, E. Galardi, E. Meli, D. Nocciolini, L. Pugi, A. Rindi, "Energy and wear optimization of train longitudinal dynamics and of traction and braking systems", Vehicle System Dynamics, 53 (5), pp. 651-671, (2015), doi: 10.1080/00423114.2014.990466.

[22] A. Frilli, E. Meli, D. Nocciolini, L. Pugi, A. Rindi, "Energetic optimization of regenerative braking for high speed railway systems, Energy Conversion and Management, 129, pp. 200-215, (2016), doi: 10.1016/j.enconman.2016.10.011

[23] S. Acikbas, M.T. Soylemez, "Parameters affecting braking energy recuperation rate in dc rail transit", Joint Rail Conference, ASME/IEEE, pp. 263-268, ASME Transportation Div., ASME ICE Division, New York, NY, 2007.

[24] J.G. Yu, M.P. Schroeder, D. Teumim, "Utilizing Wayside Energy Storage Substations in Rain Transit Systems- Some Modelling and Simulation Results", American Public Transportation Association Technical Forums, Energy, Environment and Transit, 2010. 
[25] S. Jung, H. Lee, K. Kim, H. Jung, H. Kim, G. Jang, “A Study on Peak Power Reduction using Regenerative Energy in Railway Systems through DC Subsystem Interconnection", Journal of Electrical Engineering Technology Vol. 8, No. 5: 1070-1077, 2013 http://dx.doi.org/10.5370/JEET.2013.8.5.1070 Accessed October 26, 2015.

[26] M. Miyatake, H. Ko, "Optimization of Train Speed Profile for Minimum Energy Consumption", IEEJ Trans Elec. Electron Eng., 5: 263-269, 2010. doi: $10.1002 /$ tee. 20528

[27] L. Pugi, M. Malvezzi, S. Papini, G. Vettori, "Design and preliminary validation of a tool for the simulation of train braking performance", Journal of Modern Transportation, 21(4), pp. 247-257, (2013), doi: 10.1007/s40534-013-00276.

[28] G.J. Hull, "Simulation of Energy Efficiency on Commuter Railways", Master's Thesis, University of Birmingham, 2009.

[29] W.W. Hay, "Railroad Engineering", $2^{\text {nd }}$ Edition, John Wiley \& Sons Inc., New York, USA, 1982.

[30] W. Sivanagaraju, M. Balasubba Reddy, D. Srilatha, "Generation and Utilization of Electrical Energy", Pearson Education, India, 2010.

[31] N. Zhao, "Railway Traction and Power System Energy Optimisation", University of Birmingham, https://www.birmingham.ac.uk/Documents/collegeeps/mathematics/events/2018/ning-zhao-presentation.pdf Accessed September 7th, 2018. 